\title{
Comparison between laparoscopic and subcostal mini- incision for live donor nephrectomy
}

\author{
Comparação entre a nefrectomia laparoscópica e a nefrectomia subcostal como acessos \\ cirúrgicos para nefrectomia do doador
}

Hideki Kanashiro ${ }^{1}$, Roberto Iglesias Lopes 2 , Fernando Akira Saito 3 , Anuar Ibrahim Mitre ${ }^{4}$, Francisco Tibor Denes
José Luis Chambô

\section{ABSTRACT}

Objectives: The aim of this study was to compare the results of laparoscopic donor nephrectomy with open donor nephrectomy. Methods: A non-randomized prospective analysis was conducted of living donor kidney transplantations (118 open donor nephrectomies; 57 laparoscopic donor nephrectomies) between January 2005 and December 2007 in the Kidney Transplantation Unit of Hospital das Clínicas of Faculdade de Medicina of the Universidade de São Paulo. Results: Mean donor operative time, mean donor hospital stay, mean postoperative creatinine values, and rates of complications and graft survival were similar for both groups. A significant statistical difference in warm ischemia time was observed between the open donor nephrectomy and laparoscopic donor nephrectomy groups ( $p$ $<0.001$ ). There was only one conversion in the laparoscopic donor nephrectomy group. Conclusions: Laparoscopic donor nephrectomy is a safe procedure for a donor nephrectomy, comparable to an open procedure with similar results despite a longer warm ischemia time.

Keywords: Kidney; Nephrectomy; Laparoscopy; Kidney transplantation; Tissue donors

\section{RESUMO}

Objetivos: 0 objetivo deste estudo foi comparar a nefrectomia radical laparoscópica e a nefrectomia subcostal do doador. Métodos: Foi realizado um estudo prospectivo e não randomizado dos pacientes submetidos entre Janeiro 2005 e Dezembro 2007 a nefrectomia para doação renal na Unidade de Transplante Renal do Hospital das Clínicas da Faculdade de Medicina da Universidade de São Paulo (118 casos de nefrectomia subcostal do doador; 57 casos de nefrectomia radical laparoscópica). Resultados: Tempo cirúrgico, tempo de internação hospitalar do doador, creatinina sérica pós-transplante e taxas de complicação e da sobrevida do rim transplantado foram similares para ambos os grupos. Foi encontrada uma diferença estatisticamente significante no tempo de isquemia quente $(p<0,001)$. Houve somente uma conversão no grupo submetido a nefrectomia laparoscópica. Conclusões: A nefrectomia laparoscópica do doador é procedimento seguro para doação renal e com resultados similares à nefrectomia subcostal, apesar de maior tempo de isquemia quente.

Descritores: Rim; Nefrectomia; Laparoscopia; Transplante de rim; Doadores de tecidos

\footnotetext{
Study carried out at Unidade de Transplante Renal of Hospital das Clínicas of Faculdade de Medicina of the Universidade de São Paulo - USP - São Paulo (SP), Brazil.

${ }^{1}$ Assistant physician at Hospital das Clínicas of Faculdade de Medicina of the Universidade de São Paulo - USP, São Paulo (SP), Brazil.

${ }^{2}$ MD; Urologist at Hospital das Clínicas of Faculdade de Medicina of the Universidade de São Paulo - USP, São Paulo (SP), Brazil.

${ }^{3} \mathrm{MD}$; Urologist at Hospital das Clínicas of Faculdade de Medicina of the Universidade de São Paulo - USP, São Paulo (SP), Brazil.

${ }^{4}$ Post-doctorate degree; Lecturer at Faculdade de Medicina of the Universidade de São Paulo - USP, São Paulo (SP), Brazil.

${ }^{5}$ Post-doctorate degree; Lecturer at Faculdade de Medicina of the Universidade de São Paulo - USP, São Paulo (SP), Brazil.

${ }^{6}$ Assistant physician, at Hospital das Clínicas of Faculdade de Medicina of the Universidade de São Paulo - USP, São Paulo (SP), Brazil.

${ }^{7}$ Physician assistant at Hospital das Clínicas of Faculdade de Medicina of the Universidade de São Paulo - USP, São Paulo (SP), Brazil.

${ }^{8}$ Assistant physician at Hospital das Clínicas of Faculdade de Medicina of the Universidade de São Paulo - USP, São Paulo (SP), Brazil.

${ }^{9}$ Assistant physician at Hospital das Clínicas of Faculdade de Medicina of the Universidade de São Paulo - USP, São Paulo (SP), Brazil.

${ }^{10}$ Full professor at Faculdade de Medicina of the Universidade de São Paulo - USP, São Paulo (SP), Brazil.

Corresponding author: Roberto Iglesias Lopes - Rua Baronesa de Itu, 721, apto. 121 - São Paulo - CEP 01231-001 - São Paulo (SP), Brasil - Tel.: $113666-8291$ - E-mail: robertoiglesias@terra.com.br

This paper did not have any sponsors.

The authors declare there is no conflict of interest.

Received: Apr 22, 2010 - Accepted: Oct 08, 2010
} 


\section{INTRODUCTION}

Kidney transplantation remains the mainstay treatment for end-stage chronic renal insufficiency. Live donor renal transplantation has several advantages over cadaveric transplants, such as longer patient and graft survival, shorter wait on the renal transplant list, optimal conditions for allograft retrieval, improved HLA matching, shorter cold ischemic time, and decreased immunosuppression regimens ${ }^{(1)}$. In Brazil, the number of live donors for renal transplantation has been increasing over the last years, answering for up to $50 \%$ of kidney transplantations ${ }^{(2)}$.

Performance of donor nephrectomies can be either open (by lumbotomy or subcostal access) or laparoscopic (hand-assisted procedures and pure laparoscopic). Dorsal lumbotomy has always been the golden standard for kidney procedures. However, its morbidity has motivated urologists to look for different accesses to this organ. Subcostal incisions have proven to be as efficient as lumbotomy for donor nephrectomy with clear advantages regarding late postoperative morbidity ${ }^{(3-4)}$.

Laparoscopic donor nephrectomy was first described in 1995 by Ratner et al. ${ }^{(5)}$. Since then, many centers around the world started performing this procedure due to its benefits, including early recovery, less pain and surgical site complications. A $25 \%$ increase in donations has also been reported attributed to this approach ${ }^{(6)}$.

\section{OBJETIVE}

The aim of this study was to compare the laparoscopic donor nephrectomy with the subcostal mini-incision

Table 1. Group composition

\begin{tabular}{lcc}
\hline Data & Open & Laparoscopic \\
\hline Age & $41.4 \pm 7.66$ & $38.6 \pm 10.09$ \\
BMl & $25.69 \pm 2.76$ & $25.96 \pm 3.19$ \\
Male:female & $48: 70$ & $28: 29$ \\
\hline
\end{tabular}

BMI: body mass index. open donor nephrectomy regarding perioperative results, complications and graft survival.

\section{METHODS}

A total of 175 live donor nephrectomies performed from January 2005 to December 2007 were prospectively evaluated. The study was approved by the Research Ethics Committee and informed consent was obtained. Clinical data of donors who underwent open subcostal nephrectomy (118 cases) and laparoscopic nephrectomy (57 cases) were collected. Group composition may be seen in Table 1. Because of the anatomy of the renal vascular pedicle, the laparoscopic approach was performed only on the left kidney and the subcostal anterior approach was used for both sides. Pre-operative investigation included a three-dimensional abdominal CT scan to identify venous and arterial anatomy, creatinine clearance, abdominal ultrasonography, besides immunologic and cardiologic studies. The choice of the kidney followed the principle of always leaving the best kidney for the donor. If the chosen kidney was the right one, an anterior subcostal laparotomy was performed. If it was the left one, either laparoscopic or an anterior left subcostal incision was performed, considering the surgeon's technical preference or equipment availability.

Hydration was performed exclusively with crystalloid solution from the beginning of the surgical procedure. Mannitol 10\% was slowly infused by an intravenous line continuously intraoperatively. Before clamping and sectioning the renal pedicle, mannitol infusion was accelerated to maintain hyper hydration and to promote adequate diuresis $(2-3 \mathrm{ml} / \mathrm{kg} /$ hour$)$. During induction, a dose of broad spectrum cephalosporin was given and dipyrone and opioids were used for analgesia. Analgesics were maintained after surgery according to patient's perception of pain, and cephalexin was maintained for three days after patient discharge (generally, the hospital stay was three days as seen in Table 2.

Table 2. Perioperative variables

\begin{tabular}{lccc}
\hline Data & Open & Laparoscopic & p-value \\
\hline Operative time (minutes) & $180.51 \pm 26.23$ & $257.63 \pm 28.00$ & 0.798 \\
Hospital stay (days) & 3 & 3.47 & Ns \\
Warm ischemia (seconds) & $85.95 \pm 23.55$ & $250.21 \pm 55.82$ & $<0.001$ \\
Serum Cr preoperative & $9.40 \pm 3.51$ & $9.10 \pm 3.28$ & 0.419 \\
Serum Cr 1P0 & $4.05 \pm 2.43$ & $3.88 \pm 1.88$ & 0.196 \\
Serum Cr 3P0 & $2.53 \pm 2.24$ & $2.08 \pm 1.47$ & 0.81 \\
Serum Cr 5P0 & $2.34 \pm 2.37$ & $1.73 \pm 1.35$ & 0.03 \\
Serum Cr 10P0 & $1.97 \pm 2.07$ & $1.49 \pm 1.38$ & 0.05 \\
Serum Cr 30P0 & $1.36 \pm 0.92$ & $1.37 \pm 1.32$ & 0.843 \\
Serum Cr 90 P0 & $1.26 \pm 0.56$ & $1.25 \pm 0.81$ & 0.682 \\
Serum Cr 1 year & $1.23 \pm 0.59$ & $1.14 \pm 0.31$ & 0.149 \\
Serum Cr 2 years & $1.17 \pm 0.52$ & $1.15 \pm 0.40$ & 0.853 \\
\hline
\end{tabular}




\section{Subcostal procedure}

Patients were submitted to general anesthesia and positioned laterally at $60^{\circ}$ angle, and an oblique incision was made parallel to the tip of the rib beginning at the lateral border of the rectus abdominal muscle toward the flank. Skin, subcutaneous tissue, all three muscular layers, and lumbar fascia were incised avoiding injuries to the subcostal nerve. The peritoneum was reflected with blunt dissection and the retroperitoneal space was entered reflecting the peritoneum medially when the left kidney was chosen, whereas a transperitoneal approach was preferred for the right kidney.

Once Gerota's fascia was reached, the kidney was dissected out of the surrounding fat tissue, with special care to avoid lesions to the gonadal vein and the adrenal gland. After parenchymal dissection, the vessels were carefully dissected up to their origins and freed from the lymphatic tissue. Vessels were ligated and the ureter was also dissected at the farthest point possible, keeping the fat tissue around it. After kidney removal, hemostasis was checked, and closure of the abdominal wall was performed joining the transversal and internal oblique muscles together with the external muscles in a continuous suture. The subcutaneous tissue and the skin were closed using an intradermal suture.

\section{Left laparoscopic nephrectomy}

Patients were submitted to general anesthesia followed by orogastric and urethral catheter insertion. Patients were positioned in oblique decubitus at $45^{\circ}$ over pads, elevating the left side. The left forearm was fixed in an arch-shape to the surgical table.

Pneumoperitoneum was achieved with a Veress needle introduced into the upper margin of the umbilical scar and maintenance pressure was $16 \mathrm{mmHg}$. The first puncture was performed blindly with a disposable $10-\mathrm{mm}$ retractile-tip trocar (Endopath, Ethicon Endosurgery Inc.) in the umbilicus. This trocar served as access for the laparoscope, usually at $30^{\circ}$. Another puncture in the median line slightly below the xyphoid process, measuring $5 \mathrm{~mm}$, was performed for introduction of the forceps for the assistant. Two other trocars were placed along the left anterior axillary line, with 5 and $10 \mathrm{~mm}$ respectively, for the surgeon. A Pfannenstiel transverse suprapubic incision was made through which the graft was removed.

Following inspection of the peritoneal cavity, the splenic angle and descending colon were broadly detached, maintaining Gerota's perirenal fascia intact. Throughout the procedure, monopolar electrocautery or harmonic scalpel were used for hemostasis. The upper pole of the left kidney was initially and preferentially dissected, separating it from the adrenal gland. The ureter and gonadal vessels were identified close to the crossover of the iliac vessels. Dissection continued, cranially and always medially to the gonadal vein (aiming to preserve the ureteral vascularization) until the left renal vein. The ureter was sectioned close to the crossover with the iliac vessels and clipped with a $5-\mathrm{mm}$ polypropylene clip (Hem-o-lock $\left.{ }^{\circledast}\right)$. The ligation was performed with Hem-o-locks ${ }^{\circledast}$, with subsequent sectioning of the gonadal vein close to the renal vein. The renal artery was then dissected, close to the aorta, completing the circumferential dissection of the left renal vein. Next, Gerota's fascia was anteriolaterally opened exposing the left kidney surface, which was totally released from the perirenal fat. After dissection, two 5-mm Hem-o-locks ${ }^{\circledR}$ were placed for each artery. In the same fashion, the vein was clipped with two 10$\mathrm{mm}$ Hem-o-locks ${ }^{\circledast}$ and then sectioned. The kidney was placed inside a plastic bag (Endocath II, Auto Suture, USSC) which was closed and retrieved by the Pfannenstiel incision or the kidney was retrieved by the hand of surgical assistant through a Pfannenstiel incision performed at this time.

\section{Recipients}

The kidneys were implanted through a standard extraperitoneal Gibson incision in all recipients. Endto-side vascular anastomosis between renal vessels and external iliac vessels, as well as an extravesical ureteroneocystostomy (Lich-Gregoir technique) were performed in all recipients. Anti-IL-2 induction with steroids, mycophenolate mofetil, and tacrolimus or cyclosporine was used in the recipients as immunosuppression regimen.

\section{Statistical analysis}

All continuous variables are expressed as means \pm standard deviation. Normally distributed continuous variables were analyzed using Student's $t$-test. Continuous variables not normally distributed were analyzed using the Mann-Whitney U test. Categorical variables were compared using the $x^{2}$ test or Fisher's exact test. The graft survival rates over time were assessed by Kaplan-Meier survival analysis and were compared by the log-rank test according to the studied variables. A multivariate Cox proportional hazards model was used to determine the independent predictors of graft failure. A p-value of 0.05 was adopted as the level of statistical significance. 


\section{RESULTS}

Patients submitted to different techniques were considered statistically similar, except for age. The baseline characteristics of the donors who underwent laparoscopic donor nephrectomy or subcostal donor nephrectomy are detailed in Table 1 . Donors who underwent laparoscopic procedures were younger (mean $38.6 \pm 7.6$ years) than those who were submitted to open donor nephrectomy (mean $41.4 \pm 10.1$ years). Anatomic variations regarding renal vessels were more frequently observed in the group submitted to open surgery (16.9\% in the open surgery group versus $10.5 \%$ multiple arteries in the laparoscopic group).

A comparison of the perioperative variables in the two study groups is provided in Table 2. Operative time was longer for the laparoscopic group $(257.6 \pm 28$ minutes versus $180.5 \pm 26.2$ minutes) with a significantly higher warm ischemic time in this group. Operative complications reported in Table $3 \mathrm{~A}$ and $\mathrm{B}$ were similar for both groups (difference was nonsignificant). However, it is worth noting that complications in the laparoscopic group were twice as frequent as in

Table 3A. Major complications in donors

\begin{tabular}{lccc}
\hline Data & Open (n) & Laparoscopic (n) & \\
\hline Blood transfusion & 2 & 2 & Ns \\
Re-operation & 2 & 2 & Ns \\
Conversion & - & 1 & \\
\hline
\end{tabular}

Table 3B. Surgical complications of recipients

\begin{tabular}{lccc}
\hline Data & Open (n) & Laparoscopic (n) & \\
\hline Surgical site infection & 4 & 1 & Ns \\
Hematoma/seroma & 4 & 1 & Ns \\
Incisional hernia & 2 & 1 & Ns \\
Urinary fistula & 4 & 2 & Ns
\end{tabular}

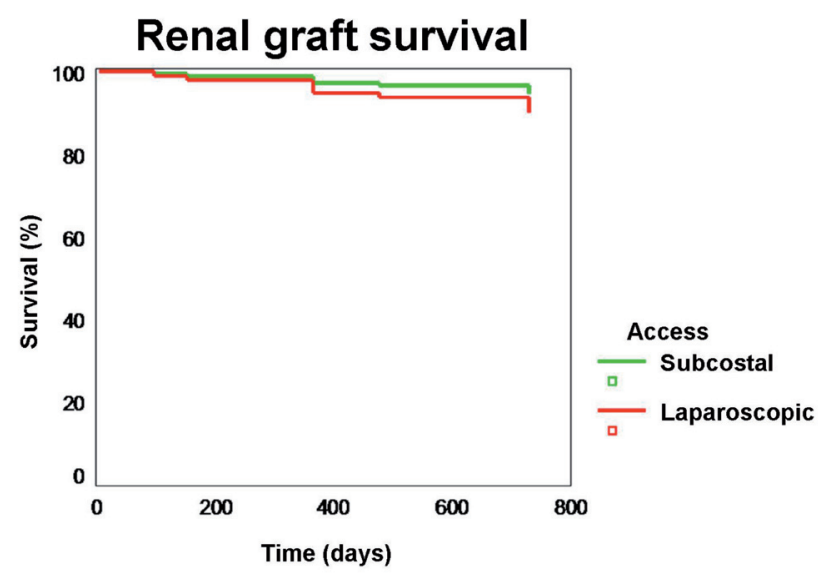

Figure 1. Comparing survival of renal transplant according to surgical approach used the subcostal group. Postoperative serum creatinine showed a statistically significant difference on the fifth and on the tenth postoperative day between the groups with early recovery in the laparoscopic group. Longterm graft function and survival showed no differences between the groups (Figure 1, $\mathrm{p}=0.8$ ) .

Postoperative pain and the need for postoperative analgesics were not evaluated in this study.

\section{DISCUSSION}

Differences in the pedicle between right and left kidneys forced the surgeon to select the cases. For this reason, the right kidney was always chosen for open subcostal nephrectomy. Additionally, left kidneys with multiple arteries or shorter veins were also chosen for open surgery. This may explain the higher incidence of anatomical variation in the open surgery group. The presence of a shorter vein on the right side and a described higher risk of venous thrombosis explain the preference for an open procedure in the majority of centers.

Initially, the presence of multiple arteries was an indication for an open procedure at our institution. Currently, it does not represent a limitation for a laparoscopic procedure.

Laparoscopic donor nephrectomy results in longer operative time and longer warm ischemia. However, none of this data has jeopardized primary graft function or has put at risk graft and patient survival. Rates of complications and graft survival were similar in both groups, similar to what has been reported by other groups, although a higher rate of complications was observed in the laparoscopic group, probably related to the learning curve of this approach ${ }^{(7-10)}$.

Laparoscopic operative time and disposable material used for this procedure enhance the overall transplantation costs. Conversely, cosmetic results of laparoscopic donor nephrectomy surpass this inconvenience and also stimulate live donor nephrectomy. Another reported benefit of the laparoscopic approach previously reported by our group is decreased postoperative pain, which was not evaluated in this study ${ }^{(11)}$. An additional limitation to our study was the non-randomization of patients.

The lack of possibility of performing safe laparoscopic right donor nephrectomies compelled the surgeons to use open surgery, which with subcostal access, has decreased morbidity when compared to lumbotomy ${ }^{(10)}$. Laparoscopic donor nephrectomy is a safe procedure. Surgeons must be prepared to open conversion when necessary (major intraoperative complications). We had two major complications in 
each series. With open nephrectomy, two patients required reoperation due to bleeding of the gonadal vein. In the laparoscopic group, one patient was reoperated due to bleeding of the gonadal vein (conversion needed) and one patient was reoperated due to a pancreatic fistula.

\section{CONCLUSION}

Laparoscopic donor nephrectomy is a safe procedure for a donor nephrectomy comparable to an open procedure with similar graft survival despite a longer warm ischemia time.

\section{REFERENCES}

1. Waples MJ, Belzer F0, Uehling DT. Living donor nephrectomy: a 20-year experience. Urology. 1995;45(2):207-10.

2. Garcia VD. Crescimento estável e como previsto. Registro Brasileiro de Transplantes. 2010; 16(2). Editorial. [Internet]. 2010 [citado 2010 Out 2008]. Disponível em: http://www.abto.org.br/abtov02/portugues/rbt/2010/RBT Semestral_1_2010_geral.pdf
3. Mitre Al, Dénes FT, Piovesan AC, Simões FA, Castilho LN, Arap S. Laparoscopic nephrectomy in live donor. Int Braz J Urol. 2004;30(1):22-8.

4. Lewis GR, Brook NR, Waller JR, Bains JC, Veitch PS, Nicholson ML. A comparison of traditional open, minimal-incision donor nephrectomy and laparoscopic donor nephrectomy. Transpl Int. 2004;17(10):589-95.

5. Ratner LE, Ciseck LJ, Moore RG, Cigarroa FG, Kaufman HS, Kavoussi LR. Laparoscopic live donor nephrectomy. Transplantation. 1995;60(9):1047-9.

6. Ratner LE, Montgomery RA, Kavoussi LR. Laparoscopic live donor nephrectomy: the four year Johns Hopkins University experience. Nephrol Dial Transplant. 1999;14(9):2090-3.

7. Lind MY, ljzermans JN, Bonjer HJ. Open vs laparoscopic donor nephrectomy in renal transplantation. BJU Int. 2002;89(2):162-8.

8. Wilson CH, Bhatti AA, Rix DA, Soomro NA. Comparison of laparoscopic and open donor nephrectomy: UK experience. BJU Int. 2005;95(1):131-5.

9. Simforoosh N, Basiri A, Tabibi A, Shakhssalim N, Hosseini Moghaddam SM. Comparison of laparoscopic and open donor nephrectomy: a randomized controlled trial. BJU Int. 2005;95(6):851-5.

10. Lee KS, Hong JH, Jeon SS, Choi HY, Kim SJ, Lee SW. Comparison of graft survival in live donor nephrectomy: hand-assisted laparoscopic $\mathrm{V}$ open procedures. J Endourol. 2004;21(8):866-71.

11. Mitre Al, Dénes FT, Nahas WC, Simões FA, Colombo Jr JR, Piovesan AC, et al.Comparative and prospective analysis of three different approaches for livedonor nephrectomy. Clinics (São Paulo). 2009;64(1):23-8. 